\title{
Spontaneous Lung Herniation after Coughing: A Case Series
}

\section{Robbert Jan Herman Knoef*, TM Wemeijer, P Steenvoorde and R de Groot}

Surgical Department, Medisch Spectrum Twente, Enschede, The Netherlands

*Corresponding author: Robbert Jan Herman Knoef, Surgical Department, Medisch Spectrum Twente, Koningsplein 1, $7512 \mathrm{KZ}$ Enschede, The Netherlands

\begin{abstract}
Background: Lung tissue protruding out of the thoracic cavity is called a lung hernia. Although most often acquired, spontaneous herniation of the lung occurs in only a small number of patients. Surgical intervention can be considered in symptomatic patients; however, little is known about used procedures and outcomes.

Case description: This case series describes the presentation, treatment and postoperative outcomes of two patients with a spontaneous lung hernia.

Conclusion: The spontaneous lung hernia is an exceptionally rare condition. Knowledge and recognition are key as a lung hernia can have potentially life threating pulmonary complications. Lung hernia can be missed on plain chest radiography which makes CT-imaging the gold standard in diagnosis. Surgical intervention should be considered in symptomatic patients as this is a safe and effective treatment.
\end{abstract}

\section{Introduction}

Herniation of the lung is defined as lung tissue protruding outside of the chest cavity boundaries through a defect in the diaphragm or thoracic wall [1]. This rare condition was first described in 1499 [2]. Lung hernias are categorized according to anatomy and etiology [3]. Based on anatomy, they can be divided into cervical, intercostal (thoracic) and diaphragmatic. The etiology can be traumatic, spontaneous or pathologic as a result of neoplastic or inflammatory processes [1].

The majority of lung hernias are acquired whereas only one in every five occurrences is the result of congenital anomalies [4]. Trauma and preceding operative procedures are the most common causes for lung herniation. However, in a small fraction of acquired lung hernias there is no history of surgery or thoracic trau- ma. These hernias are referred to as 'spontaneous' lung hernias and in over multiple decades, only a small number of cases were reported.

Spontaneous lung hernias can occur in both the thoracic and cervical regions of the thorax [5]. Although called spontaneous, these lung hernias are generally the outcome of events leading to a sudden increase in intrathoracic pressure such as coughing, sneezing or heavy lifting with subsequent rupture of the intercostal muscles or even rib fracture [4]. There are only a few studies concerning this condition and potential risk factors have only been speculated. A particularly frequent comorbidity in patients with a spontaneous lung herniation is Chronic Obstructive Pulmonary Disease (COPD), presumably as a result of chronic coughing and hyperinflation of the lung, perhaps combined with long-term steroid administration [6,7]. Brock, et al. reported 2 cases and reviewed another 16 separate cases of which all patients were male, making gender another possible risk factor. Other studies on spontaneous anterior hernias also revealed a third of the patients to be obese and to have a history of smoking [4].

The classical manifestation in symptomatic patients is pain which increases with coughing or straining. On examination it's common to find chest wall ecchymosis and a soft, bulging, subcutaneous mass that protrudes from the chest wall and enlarges with the Valsalva maneuver, couching or physical strain. Plain chest radiography may demonstrate a hernia, however diagnosis can be confirmed by a CT-scan $[8,9]$. Indications for operative repair include respiratory distress, an increase in pain or size of the herniation, impending incarceration or difficulty to reduce the hernia.

Although non-operative treatment by thoracic strap-

\footnotetext{
Citation: Knoef RJH, Wemeijer TM, Steenvoorde P, Groot R (2020) Spontaneous Lung Herniation after

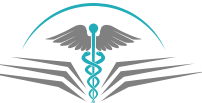

CLINMED

INTERNATIONAL LIBRARY Coughing: A Case Series. Trauma Cases Rev 6:083. doi.org/10.23937/2469-5777/1510083

Accepted: August 29, 2020: Published: August 30, 2020

Copyright: (C) $2020 \mathrm{Knoef} \mathrm{RJH,} \mathrm{et} \mathrm{al.} \mathrm{This} \mathrm{is} \mathrm{an} \mathrm{open-access} \mathrm{article} \mathrm{distributed} \mathrm{under} \mathrm{the} \mathrm{terms} \mathrm{of} \mathrm{the}$ Creative Commons Attribution License, which permits unrestricted use, distribution, and reproduction in any medium, provided the original author and source are credited.
} 


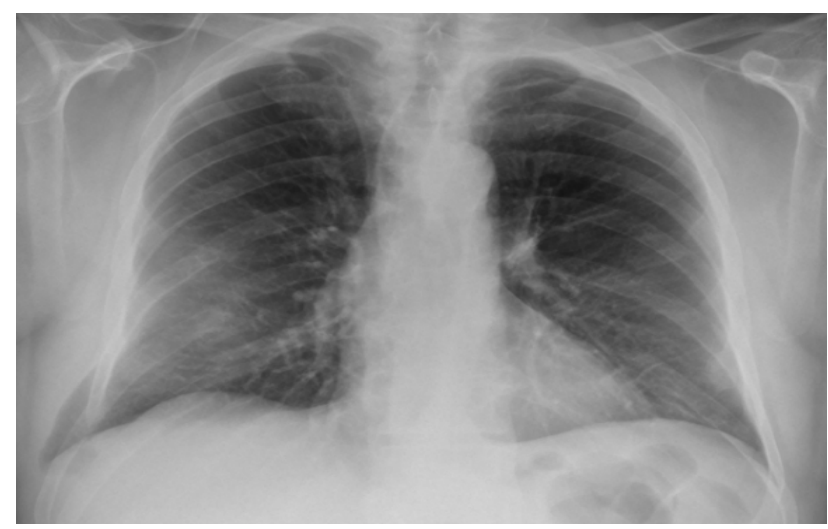

Figure 1a: Plain chest radiograph on admission shows dorsal fractures ribs 7,8 and 9 on the right side and herniation of lung tissue between ribs 7 and 8 .

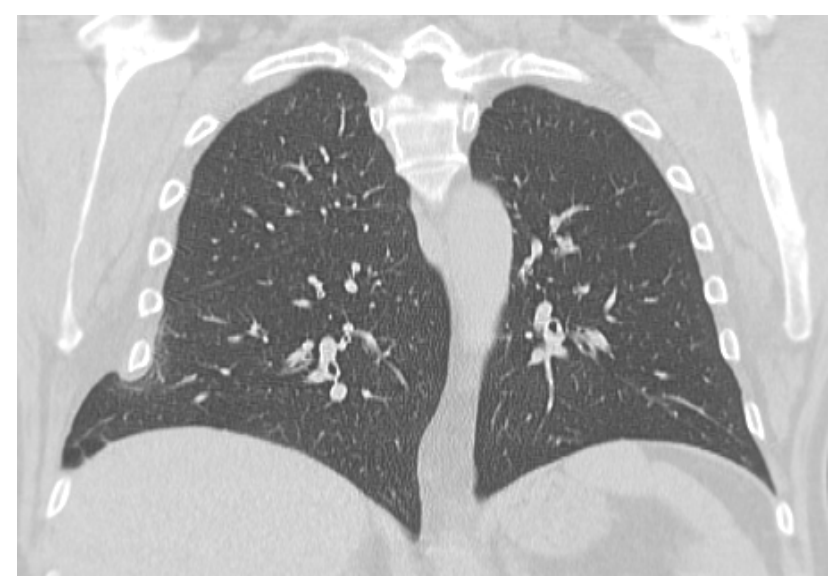

Figure 1b: Computed tomogram frontal plane view shows herniation of lung tissue between ribs 7 and 8 on the right side.

ping was often used in the past, this method has been abandoned because it reduces thoracic wall motion and thereby increases the risk of impaired respiration with subsequent atelectasis and infection [10]. Currently, most patients with symptomatic long hernias undergo early surgical repair with excellent results and low morbidity $[4,6]$.

\section{Case Description}

\section{Case 1}

A 63 year old male with a history of smoking, COPD (GOLD I) and a diagnostic laparotomy for suspected small bowel pathology followed by multiple abdominal hernia repair operations of the lower abdomen, presented at the GP with chest pain during coughing spells. The coughing spells started several weeks ago. Though anamnesis revealed no prior trauma, a chest $\mathrm{x}$-ray showed rib fractures of the $7^{\text {th }}, 8^{\text {th }}$ and $9^{\text {th }}$ ribs on the right side, accompanied by herniation of lung tissue between ribs 7 and 8 (Figure 1a). A CT-scan of the chest confirmed the diagnosis of a lung herniation (Figure 1b). Vital signs were normal, however breathing was laboured with an increased respiratory rate. The patient was admitted to the Intensive Care Unit (ICU) for observation and pain

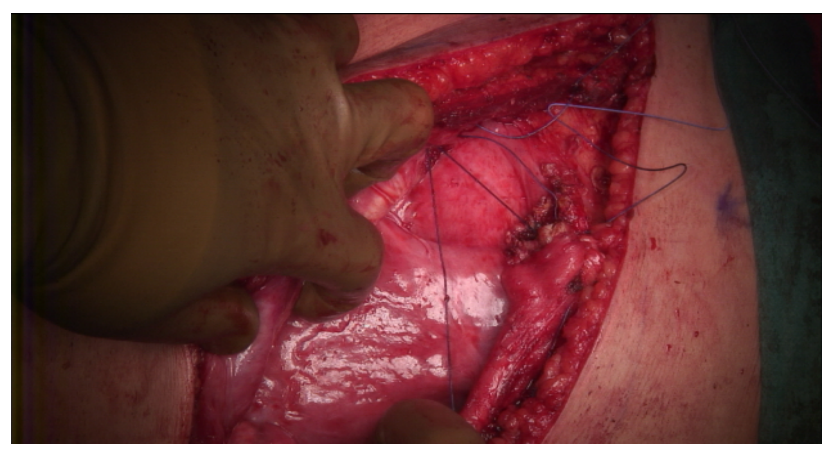

Figure 1c: Intraoperative photograph showing the herniation of lung tissue.

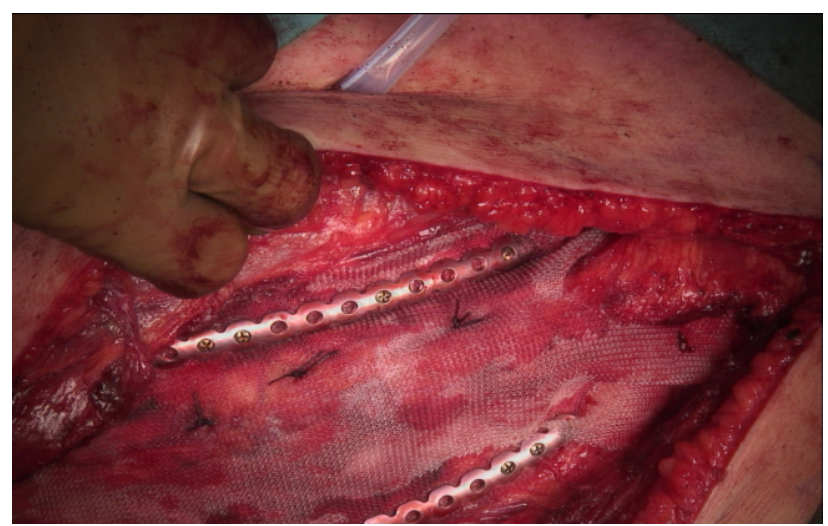

Figure 1d: Intraoperative photograph showing reconstruction of the chest wall using the MatrixRIB ${ }^{\mathrm{TM}}$ fixation system in combination with a Marlex polypropylene mesh.

management. He developed mild to moderate dyspnoea due to inadequate respiration, caused by pain for which an epidural catheter was placed. Because of further clinical decline the patient was planned for surgery. During the procedure a significant hernia sac covert by parietal pleura was found (Figure 1c). The rib cage was reconstructed using plates and vicryl sutures. Next, a polypropylene mesh was placed between the ribs for reinforcement (Figure 1d). There were no postoperative complications and in the next few days a full recovery followed. One year after surgery the patient was in good health and reported to have no discomfort during respiration or other physical discomfort.

\section{Case 2}

A 73-year-old male with a history of hypertension, obesity and smoking presented at the emergency room (ER) with complains of chest pain and dyspnoea. The symptoms had started earlier in the day with coaching spells without prior trauma. Plain X-ray of the chest showed no abnormalities, however a Computed Tomogram (CT) scan revealed distension of the $7^{\text {th }}$ and $8^{\text {th }}$ ribs on the left side with intercostal lung herniation (Figure 2). The patient was admitted to the hospital for observation and pain management. A large hematoma over the left flank developed and the patient experienced increasing respiratory distress due to pain over the next couple of days. As conservative treatment was unsuc- 


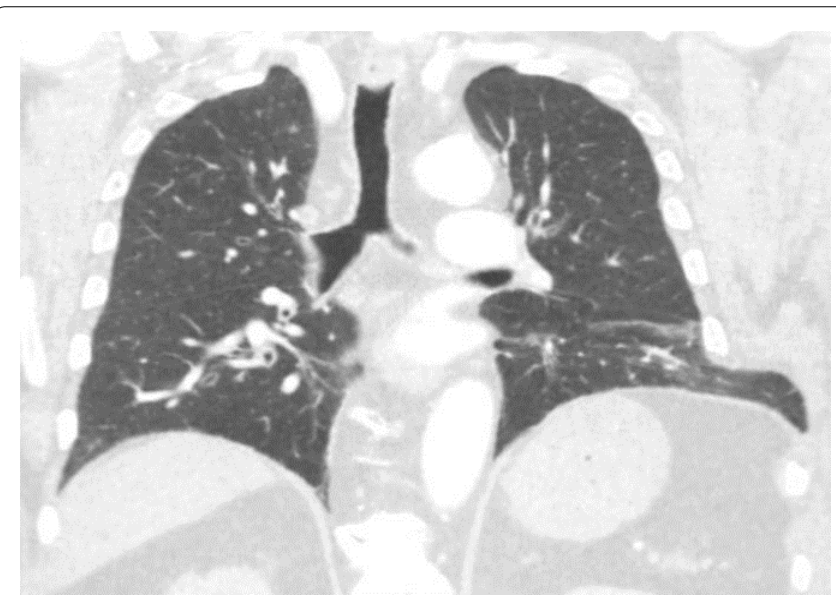

Figure 2: Computed tomogram frontal plane view shows herniation of lung tissue between ribs 7 and 8 on the left side.

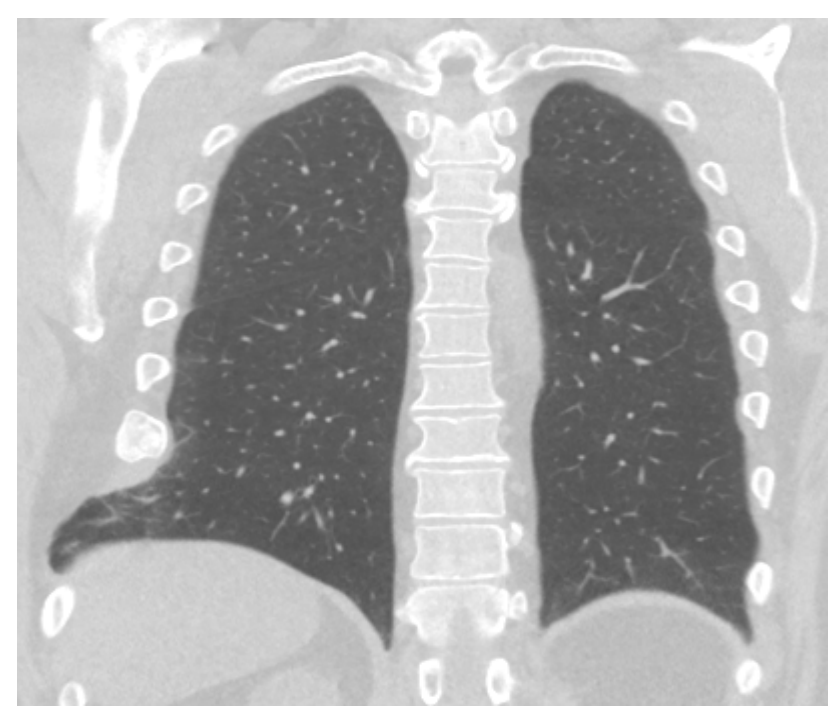

Figure 3: Computed tomogram frontal plane view shows a consolidated rib fracture of the $8^{\text {th }}$ rib on the right side with herniation of lung tissue between ribs 8 and 9 .

cessful the patient was planned for surgery. A left sided thoracotomy was performed showing a complete rupture of the intercostal musculature between ribs 7 and 8 , accompanied by herniation of lung tissue. A polypropylene mesh was placed covering the defect as an underlay beneath the ribs and secured by sutures to the overlaying ribs. Next the ribs where approximated by vicryl sutures. Postoperatively the patient made a full recovery without major complications or disability after one year of follow up.

\section{Case 3}

A 54-year-old male with a history of heavy smoking and morbid obesity presented at the clinic with pain and a palpable mass in the right thoracic wall. Anamnesis revealed no recent trauma, but the patient was involved in an accident four years ago, falling down from considerable height. Having little complaints he never visited a doctor. Years later, after having to sneeze multiple times the patient heard a clear cracking sound originat- ing from his right thorax. However, since he did not experience any pain or symptoms he neglected again to consult with a physician. Not long after, following significant weight loss, the patient noticed a painful mass on the right side of his thorax. During the physical examination a palpable bulge with a positive Valsalva maneuver was found. Plain X-ray showed rib fractures with callus formation of the $7^{\text {th }}, 8^{\text {th }}$ and $9^{\text {th }}$ ribs on the right side, no evident pulmonary abnormalities were noted. A CTscan was made revealing consolidated fractures of ribs 7 till 9 on the right side with herniation of lung tissue between ribs 7 and 8 (Figure 3). After careful consideration, taking into account the symptoms, size of the herniation and subsequent deformity of the thorax, the patient was planned for surgery. During the procedure multiple consolidated rib fractures were seen with secondary malalignment of the ribs. Between ribs 8 and 9 there was a tear of the intercostal musculature which created a defect where lung tissue protruded. The $8^{\text {th }}$ and $9^{\text {th }}$ were reconstructed with a rib plate and in the intermediate intercostal space a polypropylene mesh was placed. The first weeks of recovery were uneventful, though three weeks after surgery the patient returned to the clinic because of swelling around the site of the operation. Ultrasound revealed a large fluid collection, which after drainage turned out to be a seroma. There was no sign of infection and the patient recovered without any more complications at one year follow up.

\section{Discussion}

Herniation of lung tissue is a rare condition most often seen secondary to trauma, prior thoracic surgery or congenital anomalies. A lung hernia in the absence of prior injury is classified as spontaneous. However, spontaneous is not always an accurate term to describe the mechanism of injury as these hernias are usually the result of a sudden increase in intra-thoracic pressure following coughing or sneezing with subsequent rupture of the intercostal muscles or even rib fractures $[4,5,11,12]$. Since the first reported case by Roland in 1499 , only a few occurrences of spontaneous lung hernias have been described. Known risk factors include male gender, obesity, smoking and COPD [2,4]. Even though patients with a lung hernia can be asymptomatic, the condition can lead to significant respiratory complications including pneumonia, pneumonitis and pleural scarring, demanding frequent follow-up or surgical intervention once diagnosed [12].

In both case 1 and 2 the patients had no history of prior trauma or relevant surgeries that would make them susceptible for a lung hernia. However, both patients had potential risk factors as patient 1 had COPD and both were overweight, male and had a smoking habit. Patient 1 also had a history of COPD. Both patients experienced coughing spells, followed by dyspnoea and chest pain. Though coughing spells instigated complaints in both patients followed by dyspnoea and 
chest pain. Case 2 shows a lung herniation can be missed on X-ray, warranting further investigation by CT-scan [10]. The CT-scan in patient 2 showed distention of the ribs whereas the CT-scan of patient 1 showed multiple rib fractures. In case 3 , the patient did have a history of trauma of the thorax. However he only developed complaints years after the accident, by which time the fractures had been consolidated. Also, being male, overweight and a heavy smoker put him at increased risk for a spontaneous lung hernia. The most plausible explanation in this case is the lung hernia was acquired through increased intrathoracic pressure caused by sneezing. Labelling this lung hernia as spontaneous may be questionable however this case does highlight the important lesson that a lung hernia can occur a significant time after thoracic trauma.

During surgical repair in all three cases a rupture of the intercostal musculature was found, facilitating the herniation of lung tissue. Care must be taken to stabilize the ribs if needed and restore the integrity of the intercostal space to prevent recurrence. The use of a polypropylene mesh as a replacement of the intercostal muscles was successful in all cases, with no significant complications after a minimum of 1 year follow up.

\section{Conclusion}

A spontaneous lung hernia is an exceptionally rare condition with fewer that 300 reported cases worldwide. Knowledge and recognition are key as a lung hernia can have potentially life threating pulmonary complications. Plain X-rays of the thorax don't always show abnormalities which makes CT-scan the gold standard in diagnosing a lung herniation. Early surgical intervention should be considered in symptomatic patients as this is a safe and effective option. In all three patients presented in this case series we found excellent results at one year follow up after surgical repair, with no recurrences.

\section{Funding statement}

Nothing to declare.

\section{Conflict of Interest}

None declared.

\section{References}

1. Bhalla M, Leitman BS, Forcade C, Stern E, Naidich DP, et al. (1990) Lung hernia: Radiographic features. AJR Am J Roentgenol 154: 51-53.

2. Roland (1946) De Volmonis Sanaripot. In: de Chavliae, Guy, Cyrugia, Liber III (Cap) XXV, 144.

3. Morel-Lavalle A (1845) Hernie du poumon. Bull Mem Soc Chir Paris 1: 75.

4. Brock MV, Heitmiller RF (2000) Spontaneous anterior thoracic lung hernias. J Thorac Cardiovasc Surg 119: 10461047.

5. Tack D, Wattiez A, Schtickzelle JC, Delcour C (2000) Spontaneous lung herniation after a single cough. Eur Radiol 10: 500-502.

6. Scullion DA, Negus R, al-Kutoubi A (1994) Case report: Extrathoracic herniation of the lung with a review of the literature. Br J Radiol 67: 94-96.

7. Glenn C, Bonekat W, Cua A, Chapman D, McFall R (1997) Lung hernia. Am J Emerg Med 15: 260-262.

8. Ross RT, Burnett CM (1999) Atraumatic lung hernia. Ann Thorac Surg 67: 1496-1497.

9. Weissberg D, Refaely $Y$ (2002) Hernia of the lung. Ann Thorac Surg 74: 1963-1966.

10. Neilands PS, Kurczynski TW, EIShafie MA, Uraizee F (1991) Congenital lung herniation. Am J Med Genet 40: 9799.

11. Wani AS, Kalamkar P, Alhassan S, Farrell MJ (2015) Spontaneous intercostal lung herniation complicated by rib fractures: A therapeutic dilemma. Oxf Med Case Reports 2015: 378-381.

12. Cox M, Thota D, Trevino R (2018) Spontaneous lung herniation through the chest wall. Mil Med 183: e233-e234. 